\title{
Education or wealth: which matters more for reducing child mortality in developing countries?
}

\author{
Regina Fuchs, Elsie Pamuk, and Wolfgang Lutz*
}

\begin{abstract}
This article systematically addresses mother's education as a fundamental determinant of child mortality in developing countries. The main proposition is that setting the right policy priorities in developing countries requires distinguishing between the role of education and that of material resources in influencing child survival. Despite a tendency to regard both education and economic resources as interchangeable indicators of socioeconomic status, determining their relative importance with respect to child health is important because policies for enhancing one or the other can be quite different. We begin with a comprehensive review of the literature addressing the different causal mechanisms through which maternal education impacts on the health of her offspring. We include better maternal health, increased health-specific knowledge, adoption of non-traditional behaviours, and general female empowerment in addition to the effects of greater economic resources gained as a consequence of education. We use recent Demographic and Health Survey (DHS) data for developing countries and examine the associations between survival of the youngest child over the first year of life, the mother's educational attainment and the DHS indicator of household wealth both descriptively and using multivariate models. The results show that in the vast majority of countries and under virtually all models mother's education matters more for infant survival than household wealth. Our findings challenge frequently held views and suggest a reorientation of global health policies to more directly address increasing female education as a primary policy option for improving child health.
\end{abstract}

\footnotetext{
* Regina Fuchs (correspondence author), World Population Program, International Institute for Applied Systems Analysis (IIASA), Schlossplatz 1, 2361 Laxenburg, Austria. Email: fuchs@iiasa.ac.at

Elsie Pamuk, World Population Program, International Institute for Applied Systems Analysis (IIASA), Laxenburg, Austria.

Wolfgang Lutz, World Population Program, International Institute for Applied Systems Analysis (IIASA), Laxenburg, Austria; Vienna Institute of Demography, Austrian Academy of Sciences, Vienna, and Vienna University of Economics and Business, Vienna, Austria.
} 


\section{Introduction}

Because education and measures of economic resources, such as income or wealth, are generally highly correlated, social scientists have tended to regard them as interchangeable indicators of socioeconomic status. However, if the intention is to develop policies and interventions that will help to reduce child mortality, especially in developing countries, then it makes sense to distinguish between education and economic resources, determine if they operate independently, and find out which is more important in influencing child health.

There are prima facie reasons for focusing on maternal schooling, as opposed to household wealth, as a primary candidate for improving the health of children. With respect to her children, the mother has frequently been described as a health care worker, and often the most important one. She monitors the health of her children, diagnoses illness, performs triage, treats and follows up for complications, and within many developing countries, she is often the only source of this care. In addition, her daily decisions with respect to nutrition, hygiene and exposure to environmental hazards are a major determinant of the health of her children.

Since the seminal work by John Caldwell examined the role of maternal education on child mortality in Nigeria and outlined potential pathways through which mother's level of schooling could affect child health (Caldwell 1979), a great deal of research has focused on substantiating the independent and causal relationship between maternal schooling and child health. In the 1980s, quantitative reviews of surveys and census data from developing countries generally confirmed an association between maternal schooling and child mortality net of other factors such as father's education and occupation (Hobcraft et al. 1984; Mensch et al. 1985). The multiple country data examined by Mensch and colleagues found bivariate relationships between mother's education and child mortality indicating that each additional year of schooling was associated with an average $7 \%$ reduction (ranging from $2 \%$ to $12 \%$ ) in child death; control for all other available confounders reduced this association by about half (Mensch et al. 1985). A later econometric analysis of cross-country macro-data confirmed women's education as the most significant determinant of child mortality, with each additional year again associated with a 5\% reduction in child death (Schultz 1993). In the countries examined by Schultz, the mean education level of women increased by 3 years between 1972 and 1988, reducing child mortality by an estimated 18\% (Schultz 1993). But, critics have been quick to point out that merely establishing a strong relationship between parent's education and health of offspring, even one that remains when controlling for numerous potential confounders, does not establish a causal role for education because of the always present possibility that both the parents' education and the health of their children are, in fact, jointly determined by some other unmeasured factor or factors. 


\section{A causal role for parental education in determining child health?}

For those taking a critical approach to the role of parental education, a prime candidate for this unmeasured factor has been genetic or other background endowments of the parents that lead to both attaining higher levels of education for themselves and better health for their children. It is not only possible, but highly probable, that mothers with better health status derived from healthier childhoods convey this advantage to their children. Research has repeatedly shown that maternal height (an indicator of the mother's nutritional status as a child) is positively associated with lower infant and child mortality rates and higher birth weights and greater stature in her own offspring (Barrera 1990).

The question is to what extent does a woman's better health in childhood lead not only to better health outcomes in her offspring, but also to her attaining more education? Wolfe and Behrman, in their often cited research on the children of female siblings (including half-siblings) in Nicaragua in the late 1970s, hypothesised that childhood background characteristics determine both the mother's level of schooling and the health of her children (Wolfe and Behrman 1987). By examining only deviations of the siblings' children from each other, they concluded that maternal schooling had no independent effect on any of the child health outcomes (infant mortality and the child's height, weight and arm circumference). However, the number of families included in this study was small $(n=263)$, and variation in the amount of educational attainment between siblings is unlikely to be as large as within the female population of childbearing age as a whole.

Studies have repeatedly found that the relationship between maternal education and child mortality increases with the age of the child. Data compiled from 41 World Fertility Surveys (WFS) showed a strengthening of the relationship between maternal education and child mortality moving from infancy to deaths occurring in the second year of life to those occurring at ages 3-5 (Cleland and van Ginneken 1988). Similarly, in their 1993 review of Demographic Health Survey (DHS) data from 17 developing countries, Bicego and Boerma generally found a much stronger association between maternal education and mortality at ages 1-23 months than for neonatal mortality (Bicego and Boerma 1993). An educational differential that increases with the age of the child is consistent with maternal education becoming more important as the child's susceptibility to disease and injury becomes increasingly linked to decisions regarding nutrition, environmental exposures and treatment of disease or injury.

Thus, in his 1988 review, Cleland noted that better maternal health status was unlikely to be the major component of the maternal education and infant mortality association since better maternal health ought to convey greater advantage with respect to neonatal as opposed to later mortality (Cleland and van Ginneken 
1988). Victora and colleagues found support for this assertion by examining multiple health outcomes in a Brazilian cohort of nearly 6000 children. By controlling for family income, husband's education and other confounders, the crude relationship between maternal education and birth weight was substantially reduced and no longer statistically significant, but a strong and significant effect of mother's education remained for postneonatal mortality, hospitalisation, and nutritional indicators (Victora et al. 1992). In addition, other studies have included mother's height as an indicator of her 'health capital' in models of child health, and have found that its inclusion reduces, but does not eliminate, the effect of education on child survival (Thomas et al. 1990) or child height-for-age (Barrera 1990; Strauss 1990; Thomas et al. 1990).

Another approach to the issue of endogeneity has been to use a change in national education requirements as a natural experiment with which to measure the impact of a specific increase in parental years of schooling on child health. School reform appears to have been influential in improving infant survival and health in Taiwan. Increasing the length of compulsory education from 6 to 9 years - combined with an intensive middle school expansion program between 1968 and 1973 - was strongly linked to decreases in low birth weight, neonatal and postneonatal mortality (Chou et al. 2007). In addition, the findings from modelling this natural experiment indicated that mother's education was more important than father's, that the link between maternal education was stronger for postneonatal mortality than for either birth weight or neonatal mortality and that education could, in fact, be treated as an exogenous variable. In other words, this natural experiment yielded results consistent with more traditional analyses using the direct measurement of parental education.

In Indonesia, the intensive governmental effort at primary school construction between 1973 and 1978 has been used to examine the role of education on child mortality (Breierova and Duflo 2004). This study found that mother's and father's education, instrumented by program intensity dates and parent's ages, both contributed to decreasing infant death. It is interesting to note that the authors found some effects for schooling using the instrumental variable approach to be larger than those found using standard regression models, indicating that either the direct measurement variable for schooling contains a considerable error that biases the estimates downward, or that the instrumental variable is either highly correlated with the error term or poorly correlated with schooling, or both.

\subsection{Trend studies}

Despite the strong cross-sectional association found between maternal education and child health in diverse settings and in the same setting at different points in time, examination of the role increasing women's education has played in declines in infant or child mortality has produced more nuanced results. For example, using the Malaysian Family Life Survey to examine the relative 
contribution of maternal education, timing of births, breastfeeding, piped water and sanitation improvements on the substantial decline in infant mortality between 1946 and 1975, DaVanzo and Habicht found that increases in maternal education level explained nearly half of the reduction in the infant mortality rate over the period (DaVanzo and Habicht 1986). They also found, contrary to their expectation, that the relationship between maternal education and infant mortality was stronger during 1961-1975 than during 1946-1960, and were left to speculate that some level of economic and/or social development - infrastructure, adequate diet, available health services and information - is necessary for increases in maternal education to be effective. An examination of both fertility and infant mortality trends in Leon, Nicaragua between 1964 and 1993 led Pena and colleagues to conclude that the dramatic increase in female education instituted by the revolutionary government in 1979 was a major contributor to the overall drop in fertility during the 1980 s, but that the decline in infant mortality was primarily the result of the concomitant expansion of primary health services that mainly benefited uneducated mothers (Peña et al. 1999). Since the definition of 'uneducated' combined women with no education with those having only primary school, the analysis may have underestimated the impact of increasing basic literacy. However, the greater influence of health service expansion found in this study may result from the type of service expansion instituted in Nicaragua. In contrast, recent results from Chile show that the mortality rate of infants born to uneducated women contributed relatively little to the overall decline in the infant mortality rate (IMR) between 1990 and 1995, but that it was predominately responsible for the stagnation in the overall IMR between 2000 and 2005 (HertelFernandez et al. 2007).

\subsection{Causal mechanisms}

An alternative approach to establishing the primacy of parental, especially maternal, education in child health has been to identify the more proximate mechanisms through which education must act in order to impact health and survival. The strength of the relationship between mother's education and child health has generally been shown to be reduced, but not eliminated, when other factors, such as family income or other material resources, family size or structure, reproductive behaviour indicators (age at first birth and birth intervals), communication with spouse, female status, health information and knowledge and health services utilisation are introduced into the models (Heaton et al. 2005). These results are consistent with maternal education working through a variety of causal pathways, such as increasing economic resources, knowledge, and empowerment and through more proximate mechanisms, such as change in reproductive behaviour and health services utilisation, to improve the health of children. A review of recent evidence for each of the hypothesised causal pathways is summarised below. 


\section{Better maternal health - compressed childbearing}

To the extent that increased schooling delays childbearing into adulthood, the greater risk of infant mortality as a consequence of maternal physical immaturity is reduced. In addition, since low maternal education is associated with a larger number of children ever born and childbearing continuing late into the reproductive years in developing countries, increased education ought to reduce risks associated with late childbearing and short birth intervals (Hobcraft 1993). However, when Cleland combined data from 16 WFS surveys in developing countries, adjustment for these reproductive variables produced no reduction in the effect of 4-6 years of schooling on post-neonatal mortality, and only minimal reduction for women with 7+ years of education (Cleland and van Ginneken 1988). Similarly, in their more recent analysis of DHS survey data, Bicego and Boerma found that inclusion of 'family formation' variables (maternal age, birth order and birth interval) had either no effect or acted to increase the risk ratio of the lowest to highest maternal education group for both neonatal deaths and deaths at ages 1-23 months (Bicego and Boerma 1993).

\section{Increased health-specific knowledge}

It is often assumed that the primary effect of maternal education on child health must be through increasing knowledge related to ensuring maximal health for a given level of economic resources. However, some analysts have postulated that health-specific information is usually learned from sources other than formal schooling, such as the media and social networks. Heaton and colleagues examined this issue using DHS data from 42 countries and found that the strong relationships between 2 indicators of health knowledge (knowing about oral rehydration and the timing of conception) and infant mortality and child stunting were dramatically reduced and no longer statistically significant after controlling for formal education and economic resources (Heaton et al. 2005). This suggests that formal education either imparts specific health information or that it provides the skills necessary to absorb information available from other sources. A study in Bissau, an area of high child mortality, found that a single question proxy for health knowledge (knowing the reason for malaria) greatly diminished the substantial effect of mother's education on child mortality (Kovsted et al. 2002). While these findings might seem to imply that maternal schooling could be replaced by providing targeted - and less expensive - health-related education, especially through media sources, a study of the link between literacy skills and the comprehension of health information in urban Zambia found that the comprehension of 'decontextualised' messages - such as those of broadcast and print media - increased with more years of schooling (Stuebing 1997). More direct evidence of the symbiotic relationship between schooling and acquisition of health knowledge comes from Glewwe's analysis of Moroccan survey data (Glewwe 1999). In this study, greater maternal education decreased stunting in their children largely through increasing specific health knowledge (as measured 
by a 5-item questionnaire), but the effect was indirect in that the acquisition of health knowledge appeared to be determined by schooling having increased the mother's literacy and numeracy skills.

Examining this mechanism at a more specific level, Jalan and Ravillion found that maternal education compensated for poverty in rural India by providing knowledge related to both water safety and treatment of diarrhoea (Jalan and Ravallion 2003). They also found that a piped water source must be located within the house to compensate for the lack of this knowledge among mothers with no education. Similarly, a recent study of water sources in urban slums of Indonesia showed that households with less educated parents were more likely to purchase inexpensive drinking water, even adjusting for economic resources, and that the purchase of this poor-quality water was associated with higher rates of diarrhoea and child mortality. In addition, the multivariate models in this study indicated a strong independent effect of maternal education on both diarrhoea incidence and child mortality (Semba et al. 2009).

\section{Greater facility with 'modern' environments and adoption of non-traditional behaviours}

It has long been hypothesised that increasing education of women in developing countries improves child health by providing familiarity with more 'modern' behaviours, including personal behaviours related directly or indirectly to health and the use of 'modern' health services - as opposed to traditional sources of medical care. For example, there is ample evidence that more educated women make greater use of antenatal care during pregnancy in both more developed and less developed countries (Wong et al. 1987; Bicego and Boerma 1993; Pebley et al. 1996; Raghupathy 1996; Govingdasamy and Ramesh 1997). In developing countries, higher maternal education has been shown to be a significant predictor not only of earlier and more frequent antenatal visits, but also to a shift from traditional to modern care providers in both urban and rural settings (Wong et al. 1987).

In their analysis of DHS data from 17 developing countries, Bicego and Boerma found that the maternal education level exerted a greater influence on obtaining antenatal care during pregnancy than on any of the other outcomes considered and that this relationship remained strong and highly significant after controlling for economic resources and family formation variables (Bicego and Boerma 1993). However, introducing antenatal care into the model for neonatal and early childhood mortality had little effect on the relationship between maternal education and these outcomes. The authors were forced to conclude, "... that the types of services typically delivered in these settings do relatively little to modify mortality risk" (Bicego and Boerma 1993).

In contrast to these results, a comparison of Nigerian villages with and without a hospital found that higher maternal education combined with the availability of medical services produced a much greater reduction in child 
mortality than either the presence of services or higher maternal education alone (Caldwell and Caldwell 1985). An analysis of Malaysian data covering 19501988 also found that prenatal care and hospital delivery significantly reduced both foetal and infant mortality risks (Panis and Lillard 1994). In this study, higher maternal education not only increased demand for both prenatal care and professional delivery but also had independent, direct effects on foetal and infant mortality risks. In contrast, household income had no effect on the demand for prenatal care and its effect on infant mortality risk operated entirely through increased demand for formal sector delivery. A similar analysis using data from China for 1971-2001 found that the substantial effect of maternal education on infant mortality operated entirely through greater use of prenatal care and professional delivery, and that their advantage increased over this period despite increasing availability of these services (Song and Burgard 2008). These findings lead the authors to conclude that more educated women will always be the first to take advantage of medical innovations and improvements as they arise, maintaining education-related disparities in infant mortality despite fairly dramatic changes in the medical, social and political environment. However, studies that have looked at the relationship between maternal education and receiving tetanus toxoid during pregnancy have generally found that the relationship was considerably stronger in rural than in urban areas of developing countries, with the lack of relationship in urban areas due primarily to low rates among the most educated urban women, most likely due to a perceived low risk of neonatal tetanus by the women themselves (Raghupathy 1996) or by private doctors who judge the risk of neonatal tetanus for these women to be low (Bicego and Boerma 1993). Thus, the extent to which the adoption of modern health 'behaviours' or the use of modern health services acts as a pathway between education and infant health, is likely to depend on the effectiveness of the services in preventing child death or promoting child health and this may, in turn, depend on the nature of the health risks in the specific environment of the mother.

The difficulty with posing the adoption of 'modern' behaviours as a causal pathway between maternal education and child health is that what constitutes more 'modern' behaviour varies considerably over time and cultures. Depending on the setting, some non-traditional behaviours may well be associated with adverse, rather than better, health outcomes. The most studied example is probably breastfeeding. The switch from breast- to bottle-feeding among more educated women has been an almost universally observed phenomenon in developing countries (Cleland and van Ginneken 1988). If this occurs in settings with unsafe water or is inadequately supplemented with additional nutrition, the consequences for child health could be more detrimental to infant health than depending entirely on breastfeeding for longer durations. Support for the adverse effect of shorter durations of breastfeeding among more educated women came from the Ondo, Nigeria DHS conducted in 1986-87 (Adetunji 1995). Adetunji found that the crude infant mortality rates were similar between mothers with no 
schooling and those with some primary schooling but that mothers with secondary schooling had a significantly higher level of infant death. Adjustment for maternal age and parity reduced the odds of infant death among educated women somewhat, but adjustment for breastfeeding duration produced much greater reductions and resulted in the usual pattern of a strong negative relationship between mothers' education and the risk of infant death.

\section{Empowerment of women}

Despite Caldwell's early argument that female education works to improve child health by increasing a woman's autonomy, the literature specifically examining empowerment as a causal pathway between mother's education and child health remains quite sparse. The relatively recent analysis of DHS surveys by Heaton and colleagues found that the positive effect of couple communication and the woman's higher status (as indicated by the absence of a large age difference between spouses) on child mortality and nutritional status was diminished, but not eliminated, by controlling for the woman's education level (Heaton et al. 2005). More specifically relevant, a detailed survey of husbands and wives in western Guatemala showed that wives with secondary education were much more likely to be involved in decisions regarding what to do if a child is ill or the woman becomes ill during pregnancy, and whether or not to purchase medication if a family member is ill (Becker et al. 2006). In a study of women's autonomy and health care behaviour in northern India, Bloom found that higher education increased a woman's freedom of movement, and that this in turn increased her likelihood of receiving antenatal care when pregnant (Bloom et al. 2001).

\section{Economic resources/wealth/income}

More pertinent to address the issue in this paper is the fact that more education leads to higher income by increasing access to higher paying employment or enabling self-employment to be more economically productive. This higher income, in turn, leads to easier access to health-promoting resources (more and better food, a healthier environment or healthier living conditions within the same environment, access to preventative and curative medical care, etc.). For either parent, but particularly for the woman, this can be achieved through the woman's own employment or income-generating activities or/and through marriage to someone of similar or higher educational background.

Most analyses that include both maternal education and household economic resources within a multivariate model find that each has an independent effect on child health (Hobcraft et al. 1984; Mensch et al. 1985; Cleland and van Ginneken 1988; Bicego and Boerma 1993; Heaton et al. 2005). The extensive review of available data in developing countries conducted by Mensch and colleagues in 1985 found that approximately half of the gross association between mother's schooling and child mortality remained after control for household economic resources and/or living conditions such as dwelling characteristics, water supply 
and toilet type (Mensch et al. 1985). In their analysis of available data from the World Fertility Surveys done around the same time, Hobcraft and colleagues found that control for husband's occupation and education, mother's labour force status and rural-urban residence greatly diminished the association between maternal education and mortality in both the neonatal and post-neonatal period, but that a large and significant association remained for mortality at ages 1-5 (Hobcraft et al. 1984). The study of 17 developing countries conducted by Bicego and Boerma in 1993 found that the effect of controlling for household economic resources reduced the relationship between maternal education and both neonatal mortality and mortality at ages 1-23 months by similar, substantial amounts, but that the degree to which economic resources confounded this relationship varied considerably over the countries studied (Bicego and Boerma 1993).

This review of the existing literature has shown that studies in developing countries have tended to support a role for maternal education net of any effect that increased education has on household economic resources. However, few studies have tried to establish which of these factors, maternal education or household income, has the greater impact on the level of infant or child mortality. As pointed out in the introduction, answering this question is crucial to determining the appropriate focus of policies aimed at enhancing and sustaining improvements in child health within the developing world.

\section{Empirical analysis using global DHS data}

This study uses individual-level data from Demographic and Health Surveys conducted in developing countries that contain the necessary education and wealth indicators. Since 1984, the MEASURE DHS project has provided technical assistance to the collection of data on fertility, family planning, maternal and child health, gender, HIV/AIDS, malaria and nutrition in developing countries. The Measure DHS project is run by ICF Macro and funded by the US Agency for International Development (USAID); hence countries that participate in the DHS program are primarily but not exclusively countries that receive USAID assistance.

The DHS project was designed as a follow-up of the World Fertility Surveys (WFS) and the Contraceptive Prevalence Surveys. So far there had been 5 phases of the project DHS I-III, the MEASURE program and MEASURE DHS+. The DHS program strives to collect data that are comparable across countries. There is a basic standard questionnaire which has been modified and improved in each phase of the program. This core questionnaire covers background characteristics of women aged 15-49, their reproductive histories, knowledge and use of contraceptive methods, breastfeeding, child health and nutrition, husband's background, etc. (further details can be found in the Guide to DHS Statistics (Rutstein and Rojas 2006)). 
This study uses data from all DHS surveys from developing countries in Africa, Asia and Latin America that include a measure of economic status- the Wealth Index in the DHS Surveys. ${ }^{1}$ The Wealth Index was developed in the late 1990s by Shea Rutstein at ORC (Rutstein and Johnson 2004).

The Wealth Index is supposed to represent only economic resources. Education and occupation are deliberately left out in the calculation of the Wealth Index since they might interfere with the purely economic variables and potentially offset their effects. The DHS collects a number of assets and services available in the household, i.e. type of flooring, water supply, electricity, radio, refrigerator, domestic servants, etc. These goods are associated with a (regionally) different underlying wealth scale: the proportion of households having a TV and a refrigerator increases with wealth whereas the proportion of households with a surface source of drinking water declines with increasing household wealth. Using principal components analysis, each indicator variable is assigned a weight to generate the overall wealth score (Rutstein and Johnson 2004).

The Wealth Index is a relative index; it represents the wealth of a person or a household within a country. DHS also reports wealth quintiles which are based on the distribution of the household population (in contrast to the distribution of households). The quintiles are calculated by obtaining a weighted frequency distribution of households, household weights being the product of the household sampling weight times the number of persons living in the household. The individual scores are then ordered and divided into quintiles.

DHS collects information on education and reports the following variables: highest education level attended, highest year of education at the highest education level, highest educational attainment and education in single years. The highest education level attended includes the categories No education, Primary, Secondary and Tertiary. The highest year of education represents the number of years completed within the highest education level. The variable most appropriate for our analysis is single years of education, the third category. It is constructed from the two other variables and accounts for country-specific years of education within a given level of education (MeasureDHS+ 2008).

The DHS surveys report full birth histories of women aged 15-49 from which we estimate infant mortality for the selected countries. Even though the DHS project offers a routine which allows calculating neonatal, infant and child mortality rates, we use a simpler method which only serves as a basis for this project and should not be compared with infant mortality rates from other sources.

Infant mortality is calculated as follows: each mother is represented only once in our sample. We consider only the last child born to each woman to avoid having to estimate multi-level models that account for the clustering of children

1 We include only countries defined by the World Bank as 'low' or 'lower-middle' income countries in 2005 (World Development Indicators database, World Bank) and exclude the countries of the former Soviet Union. A full description of countries and sample sizes can be found in the Appendix. 
within households. This permits greater comparability between the descriptive and model results and also greater comparability across countries with different sample designs. The sample is censored to include only children born more than 12 months prior to the date of data collection. For women whose most recent birth occurred within the 12 months prior to the interview, we included the previous live birth (if any) in our sample. The infant mortality rates shown in the following tables represent the number of infants out of 1000 who died within their first year of life. ${ }^{2}$

\section{Cross-classifying mother's education and household wealth}

As discussed in the introduction, most studies on the determinants of child mortality simply consider socio-economic status as an indicator reflecting both educational attainment and economic resources such as income or wealth. This is appropriate when the aim is to study the extent to which infant mortality varies among social groups but it is quite unsatisfactory when the goal is to define policy priorities where the emphasis could be either on enhancing education of young women or alternatively on providing households with income subsidies or amenities that would increase their standing with respect to the DHS wealth indicator.

A frequently raised objection to efforts at disentangling educational attainment and wealth effects is that they are so highly correlated that no meaningful separation is possible. This view, however, may be attributed to the long-standing tradition of considering these two key dimensions of socioeconomic status as interchangeable, rather than being based on empirical evaluations. The whole concept of social class which is so pervasive in social sciences assumes that both are merely the reflection of the same cause, namely membership in a certain class. On the other hand most studies on social mobility do point to education as the most important avenue of upward class mobility.

In this article we try to address the question in an empirical manner by testing for the existence of independent effects of education and wealth on infant mortality and, more importantly, by attempting to establish which effect is more important.

One straightforward and convenient way to do this is to divide the weighted sample for each country into four groups that result from cross-classifying high and low education against high and low wealth. Conceptually the best way to do this is to cut the sample at the median so that all four groups would be of equal

2 Our procedure results in a reduced number of births available for analysis. As a result, Guyana and Madagascar were excluded from our sample because sample sizes in these two countries were too small to produce reliable estimates. 
size. In practice, it was not possible to cut the sample at exactly $50 \%$ of the weighted observations because of the very unequal educational distribution of women in many countries. In some countries, especially in Africa, the number of women who had never received any formal education greatly exceeded $50 \%$. In a few other countries, a very large proportion of women reported leaving school at the same level, resulting in a forced division of the sample at a cut point substantially above or below the median. Of our original sample selection of 41 countries, we excluded 14 where the education cut point was below $33.3 \%$ or above $66.6 \%$, respectively. This level was quite arbitrarily chosen but ensures that each subgroup contains a relatively high share of the overall sample. Although in theory this arbitrary rule allowed the 'high' education group to contain from onethird to two-thirds of the female population, in only 3 countries did the proportion of women in the 'high' education group fall below 40\%: Morocco (33\%), Lesotho $(35 \%)$, and Namibia (35\%). Since the Wealth Index is on a metric scale it can be easily divided at any proportionate share of the population, we matched the per cent of women in the 'high' and 'low' education groups with approximately equivalent per cents in the 'high' and 'low' wealth groups.

Figures 1-3 present such cross-tabulations for three selected countries with large sample sizes from three different continents: Colombia, Kenya and Indonesia. Each table cell contains the estimated infant mortality rate (1st line), the unweighted sample size (2nd line), and the estimated proportion of the population of women of childbearing age calculated from the weighted sample. The overall pattern of infant mortality by education and wealth in these example countries, as well as in virtually all of the countries examined, is as expected: women in the group with 'low' education combined with 'low' wealth have a much higher infant mortality rate than those in the 'high' education and 'high' wealth group. But the more interesting question to us is how poor mothers with above average education compare to their less educated, but wealthier counterparts. As expected, both of these groups have infant mortality rates between those of the two extreme groups in the upper left and lower right corners of the table. But the more interesting and not theoretically predicted finding is that almost consistently the educated poor are doing better than the uneducated with greater wealth. 
Table 1:

Infant mortality rates by low/high education and wealth categories in Colombia

\begin{tabular}{l|c|ccc}
\hline Colombia & & Low wealth & High wealth & Total \\
\hline \multirow{4}{*}{ Low education } & Infant mortality & 24.4 & 16.8 & 22.1 \\
& $\mathrm{~N}$ & 10120 & 3056 & 13176 \\
& Pop. share & 0.35 & 0.15 & 0.50 \\
\hline \multirow{3}{*}{ High education } & Infant mortality & 14.5 & 8.0 & 10.0 \\
& $\mathrm{~N}$ & 5146 & 7120 & 12266 \\
& Pop. share & 0.16 & 0.34 & 0.50 \\
\hline \multirow{4}{*}{ Total } & Infant mortality & 21.3 & 10.7 & 16.1 \\
& $\mathrm{~N}$ & 15266 & 10176 & 25442 \\
& Pop. share & 0.51 & 0.49 & 1.00 \\
\hline
\end{tabular}

Table 2:

Infant mortality rates by low/high education and wealth categories in Kenya

\begin{tabular}{l|c|ccc}
\hline Kenya & & Low wealth & High wealth & Total \\
\hline \multirow{4}{*}{ Low education } & Infant mortality & 72.7 & 65.9 & 70.5 \\
& $\mathrm{~N}$ & 2016 & 994 & 3010 \\
& Pop. share & 0.37 & 0.17 & 0.55 \\
\hline \multirow{4}{*}{ High education } & Infant mortality & 58.7 & 30.2 & 40.01 \\
& $\mathrm{~N}$ & 755 & 1776 & 2531 \\
& Pop. share & 0.16 & 0.30 & 0.45 \\
\hline \multirow{4}{*}{ Total } & Infant mortality & 68.5 & 43.3 & 56.7 \\
& $\mathrm{~N}$ & 2771 & 2770 & 5541 \\
& Pop. share & 0.53 & 0.47 & 1.00 \\
\hline
\end{tabular}

Table 3:

Infant mortality rates by low/high education and wealth categories in Indonesia

\begin{tabular}{l|c|ccc}
\hline Indonesia & & Low wealth & High wealth & Total \\
\hline \multirow{4}{*}{ Low education } & Infant mortality & 30.2 & 29.8 & 30.1 \\
& $\mathrm{~N}$ & 12132 & 3265 & 15397 \\
& Pop. share & 0.42 & 0.15 & 0.57 \\
\hline \multirow{4}{*}{ High education } & Infant mortality & 25.5 & 12.9 & 17.6 \\
& $\mathrm{~N}$ & 6063 & 7650 & 13713 \\
& Pop. share & 0.16 & 0.27 & 0.43 \\
\hline \multirow{4}{*}{ Total } & Infant mortality & 29.0 & 19.0 & 24.8 \\
& $\mathrm{~N}$ & 18195 & 10915 & 29110 \\
& Pop. share & 0.58 & 0.42 & 1.00 \\
\hline
\end{tabular}


Proximity to health care facilities may be an important intervening factor in determining the level of infant mortality, and in most developing countries urban residents have greater access to health services than residents of rural areas. Because urban populations also tend to be more educated, we also conducted a multivariate analysis using the same categorisation of 'low' and 'high' education and wealth, while controlling for urban/rural place of residence. ${ }^{3}$ The results of these country-specific logistic regression models are shown as odds ratios in Table 4.

The results shown in this table clearly indicate that higher maternal education reduces the likelihood of infant death; all odds ratios are less than one and in 18 of the 27 countries these estimates attain statistical significance. In contrast, while a higher Wealth Index also generally reduces the likelihood of infant death, not all of the odds ratios are less than one and only four are statistically significant. And while residence in an urban area also generally reduces the likelihood of infant death, in only a few countries was the 'urban' effect larger than or similar to that of mother's education.

The greater impact of higher maternal education compared to a higher Wealth Index is displayed graphically in Figure 1. The dark diagonal line indicates equality between the odds ratios for 'high' maternal education and 'high' wealth. For all but four countries, the odds ratio for 'high' education is lower (having a greater negative effect on infant mortality) than that for 'high' wealth, as indicated by the points lying to the right of the diagonal.

In Table 4, all but one of the estimated odds ratios for 'high' education with values less than 0.75 (indicated by the dashed line) were statistically significant.

3 The definition of "urban area" in the DHS corresponds to the definition used by each country when conducting their census. 
Table 4:

Odds ratios for the effects of higher educational attainment, higher Wealth Index and urban residence on the likelihood of infant death; Demographic Health Surveys from selected developing countries

\begin{tabular}{|c|c|c|c|c|c|c|c|}
\hline \multirow{2}{*}{$\begin{array}{l}\text { Country } \\
\text { Bangladesh }\end{array}$} & \multicolumn{2}{|c|}{$>$ Median education } & \multicolumn{2}{|c|}{$>$ Median wealth } & \multicolumn{2}{|c|}{$\begin{array}{l}\text { 'Urban' } \\
\text { residence }\end{array}$} & \multirow{2}{*}{$\begin{array}{c}\begin{array}{c}\text { Sample } \\
\text { size }\end{array} \\
9429\end{array}$} \\
\hline & 0.65 & $* *$ & 0.90 & & 0.81 & & \\
\hline India & 0.62 & $* * *$ & 0.64 & $* * *$ & 0.84 & $* *$ & 81248 \\
\hline Indonesia & 0.64 & $* *$ & 0.76 & & 0.99 & & 29110 \\
\hline Cambodia & 0.57 & $* * *$ & 0.82 & & 0.73 & $*$ & 10320 \\
\hline Bolivia & 0.56 & $* * *$ & 0.83 & & 0.99 & & 11691 \\
\hline Colombia & 0.55 & $* * *$ & 0.60 & $* *$ & 0.96 & & 25442 \\
\hline Dominican Rep. & 0.77 & & 0.83 & & 1.25 & & 18723 \\
\hline Haiti & 0.75 & & 1.19 & & 0.81 & & 6159 \\
\hline Peru & 0.51 & $* *$ & 0.39 & $* *$ & 1.27 & & 8155 \\
\hline Congo, DR & 0.61 & $* *$ & 0.85 & & 1.02 & & 6715 \\
\hline Congo & 0.68 & $*$ & 0.75 & & 0.97 & & 4888 \\
\hline Cameroon & 0.78 & $*$ & 0.96 & & 0.90 & & 7138 \\
\hline Egypt & 0.66 & $*$ & 0.63 & $*$ & 1.47 & $*$ & 13944 \\
\hline Ghana & 0.88 & & 0.87 & & 1.17 & & 3830 \\
\hline Jordan & 0.53 & & 0.96 & & 0.80 & & 9457 \\
\hline Kenya & 0.61 & $* *$ & 0.72 & & 1.02 & & 5541 \\
\hline Liberia & 0.83 & & 1.18 & & 0.78 & & 5409 \\
\hline Lesotho & 0.77 & & 0.81 & & 0.79 & & 4517 \\
\hline Morocco & 0.67 & $*$ & 0.71 & & 0.66 & $*$ & 8337 \\
\hline Malawi & 0.88 & & 0.95 & & 0.42 & $* * *$ & 8764 \\
\hline Mozambique & 0.71 & $* *$ & 0.87 & & 1.07 & & 9231 \\
\hline Nigeria & 0.78 & & 0.73 & & 0.91 & & 4826 \\
\hline Namibia & 0.57 & $*$ & 0.72 & & 1.08 & & 6268 \\
\hline Rwanda & 0.69 & $* * *$ & 1.04 & & 0.51 & $* * *$ & 6722 \\
\hline Swaziland & 0.71 & $*$ & 1.05 & & 0.83 & & 3280 \\
\hline Uganda & 0.78 & & 1.11 & & 0.72 & & 6123 \\
\hline Zimbabwe & 0.69 & $*$ & 1.02 & & 0.97 & & 5946 \\
\hline
\end{tabular}

Notes: Significance levels $(\mathrm{p}): *<.05 ; * *<.01 ; * * *<.001$ 
Figure 1:

Odds ratios for the likelihood of infant death in 'High' education and 'High' income groups by country

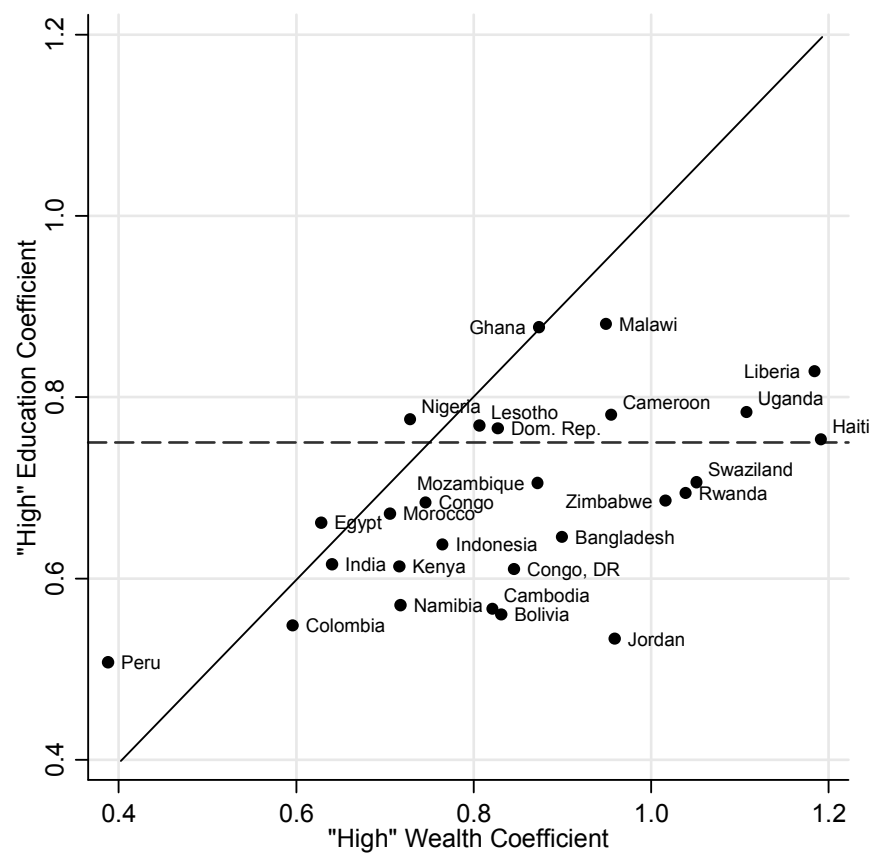

\section{Extended categorisation of education and wealth}

In the analysis shown so far, we have tried to ensure comparability between education and wealth by creating categories that have equal population shares in the higher and lower wealth and education groupings. However, limiting the analysis to only two levels of education and wealth may well conceal unobserved heterogeneity within these large sections of the population. To examine this possibility, we conducted additional analyses with extended categories of education (none, primary, secondary, tertiary) and wealth (country-specific quintiles of the Wealth Index distribution).

Table 5 shows an example of the complete set of models examined for each country (full data table available from the authors by request). 
Table 5:

Logistic model results with extended education and wealth categories: Kenya

\begin{tabular}{|c|c|c|c|c|c|c|c|}
\hline Kenya & Model 1 & Model 2 & Model 3 & & Model 4 & & $\begin{array}{c}\text { Sample } \\
\text { proportion }\end{array}$ \\
\hline$>$ Median education & $0.61 * *$ & $0.61 * *$ & & & & & 0.45 \\
\hline > Median wealth & $0.72 *$ & 0.72 & & & & & 0.47 \\
\hline Dummy urban & & 1.02 & & & 0.89 & & \\
\hline \multicolumn{8}{|l|}{ Education } \\
\hline Primary & & & 1.10 & & 1.09 & & 0.53 \\
\hline Secondary & & & 0.52 & * & 0.51 & * & 0.21 \\
\hline Tertiary & & & 0.31 & $*$ & 0.31 & $*$ & 0.06 \\
\hline \multicolumn{8}{|l|}{ Wealth } \\
\hline 2nd quintile & & & 0.82 & & 0.82 & & 0.17 \\
\hline 3rd quintile & & & 0.78 & & 0.78 & & 0.17 \\
\hline 4th quintile & & & 0.58 & $*$ & 0.59 & $*$ & 0.19 \\
\hline 5th quintile & & & 0.74 & & 0.82 & & 0.28 \\
\hline $\mathrm{N}$ & 5541 & 5541 & 5541 & & 5541 & & \\
\hline
\end{tabular}

Notes: Significance levels (p): *<.05; **<.01; ***<.001

Comparison of these various model specifications allowed us to assess the consistency of our findings from the proportionate models using a larger number of fixed categories (as opposed to population proportions) for education and quintile categories for wealth. In addition, not needing to assure comparable proportions of the population in the education and wealth categories allowed us to include all 41 countries in these extended categorisation analyses.

The findings from Model 4, which includes a dummy variable for urban residence, are summarised in Figures 2 and 3 below. Figure 2 plots the odds ratios for the likelihood of infant death for three levels of education ${ }^{4}$ relative to no education, and for quintiles 2-5 of the Wealth Index relative to the lowest quintile for all 41 countries. The unweighted, arithmetic average of the estimated odds ratios for each level of education and wealth is indicated by the dashed line in each panel. It is clear that the general tendency is for the odds ratios to declineindicating a greater likelihood of survival — with each higher level of education; and while this same tendency is seen with increasing wealth quintiles, the magnitude of the decrease is not as great.

\footnotetext{
In seven countries (Burkina Faso, Ethiopia, Guinea, Cambodia, Rwanda, Senegal and Chad) the proportion of births to mothers having tertiary education was too small to produce estimates.
} 
Figure 2:

Odds ratios for the effect of maternal education level and Wealth Index quintile on infant mortality

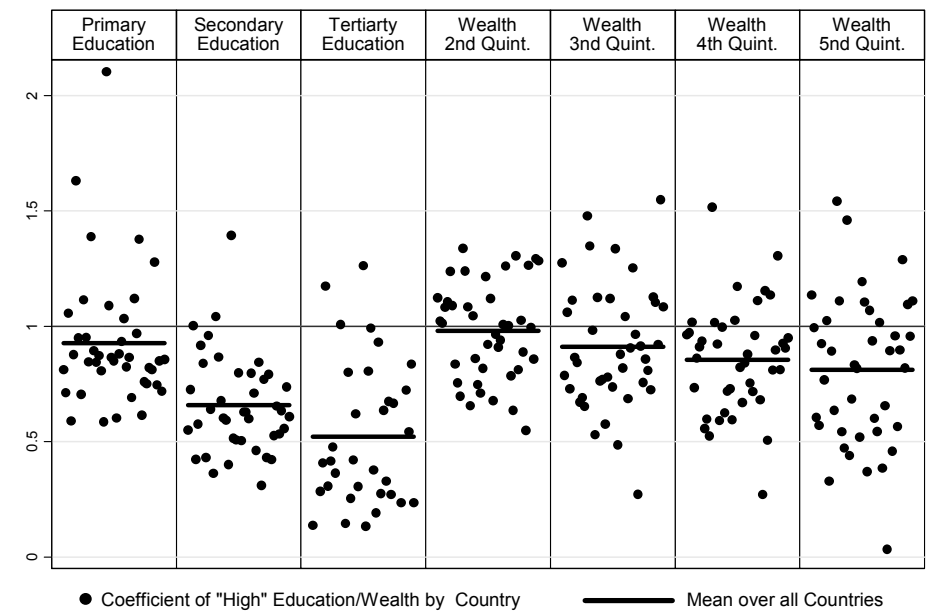

Figure 3:

Statistically significant odds ratios for the effect of maternal education level and Wealth Index quintile on infant mortality

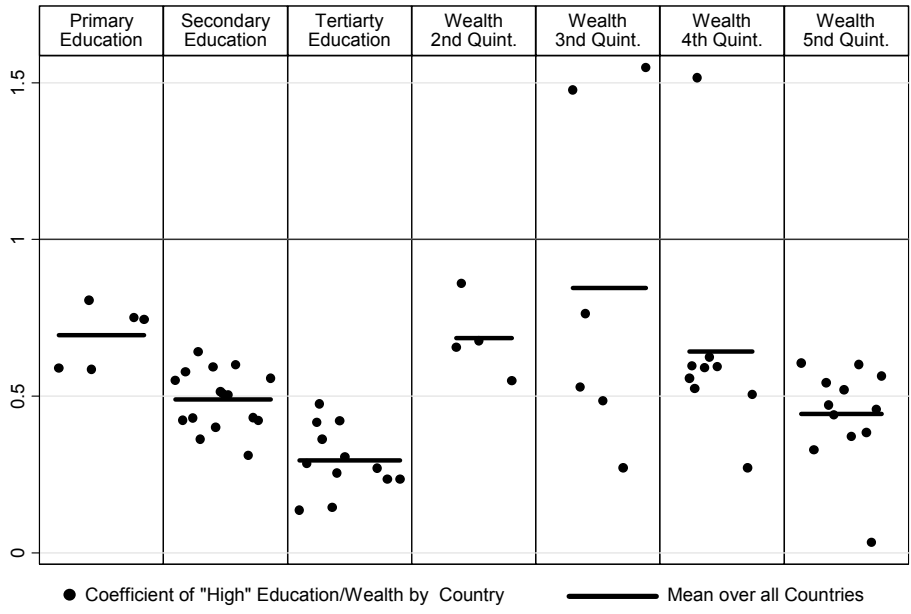

Figure 3 presents the same graphic, limited to odds ratio estimates that were statistically significant at $\mathrm{p}<.05$.

While the results for maternal education appear even stronger and more consistent when only the statistically significant coefficients are plotted, the same cannot be said for the Wealth Index. In addition, an examination of the education 
and wealth odds ratios for each country revealed a general downward trend with increasing education in 35 of the 41 countries, but a tendency toward a downward trend with increasing wealth in only 25 countries (data available on request).

\section{Conclusions}

This analysis of recently collected DHS data from developing countries produced compelling evidence that maternal education has a larger impact on infant mortality than household wealth. Comparable proportionate shares of higher education and higher wealth revealed a consistent reduction in the likelihood of infant death with higher education, with the education effect exceeding that of higher wealth for all but four of the countries examined. The analyses employing extended education and wealth categories produced results similar to those found using comparable proportionate shares in the 'low' and 'high' education and income groups; we observed a larger and more consistent tendency for the likelihood of infant death to decline with each increase in education level compared to increases in wealth quintile.

In addition, we have attempted to assess the evidence for an independent and causal relationship between the mother's education and child health as well as the evidence for particular intermediate causal pathways mediating this effect. We found that the associative evidence between maternal education level and the health of their children is overwhelming, and holds across the entire spectrum of economic development and across many different cultural settings. In addition, most studies that include competing variables, in particular household income or wealth, but also other variables such as health service availability, almost always find a significant, independent effect of maternal education and indicators of child health. We have tried to address the important but often neglected question of which of these two most often examined background factors - maternal education or household economic resources - has the greatest impact on infant mortality.

It is important to also acknowledge that analyses which model maternal education and household economic resources simultaneously from cross-sectional data do not entirely account for the influence of maternal education since better education often produces greater household wealth. While the majority of studies show that the effect of maternal education is substantially reduced once household resources are considered, many authors have acknowledged the difficulty of adequately accounting for the 'impact of education on the level of those resources (Boyle et al. 2006). Studies that have included 'the impact of education on household income using multi-stage models have found differences in the degree to which education appears to operate on child health by increasing household income (Thomas et al. 1991; Glewwe 1999). Further research, with more complex data and modelling, may be necessary to determine the extent to which increases in economic resources matter more or less than other pathways operating between 
maternal education and child health, such as reducing and compressing reproduction, increasing health knowledge, adoption of 'modern' health-related behaviours, or increasing autonomy. However, it is equally important to remember that, from a policy perspective, fully detailing the mechanisms through which maternal education operates is less important than establishing the importance of maternal education as an alterable factor greatly influencing child health.

\section{Acknowledgements}

The authors wish to acknowledge the support of the European Commission Grant ERC-2008-AdG 230195 Future Society.

\section{References}

Adetunji, J. 1995. "Infant mortality and mother's education in Ondo State, Nigeria." Social Science and Medicine 40(2): 253-263.

Barrera, A. 1990. "The role of maternal schooling and its interaction with public health programs in child health production." Journal of Development Economics 32: 29-91.

Becker, S., F. Fonseca-Becker, and C. Schenck-Yglesias. 2006. "Husbands' and wives' reports of women's decision-making power in Western Guatemala and their effects on preventive health behaviors." Social Science and Medicine 62: 2313-2326.

Bicego, G. T. and J. T. Boerma. 1993. "Maternal education and child survival: A comparative study of survey data from 17 countries." Social Science and Medicine 36(9): 1207-1227.

Bloom, S. S., D. Wypij, and M. Das Gupta. 2001. "Dimensions of women's autonomy and the influence on maternal health care utilization in a north Indian city." Demography 38(1): 67-78.

Boyle, M. H., Y. Racine, K. Georgiades, D. Snelling, S. Hong, W. Omariba, P. Hurley, and P. Rao-Melani. 2006. "The influence of economic development level, household wealth and maternal education on child health in the developing world." Social Science and Medicine 63: 2242-2254.

Breierova, L. and E. Duflo. 2004. "The impact of education on fertility and child mortality: do fathers really matter less than mothers?" NBER Working paper No. W10513.

Caldwell, J. C. 1979. "Education as a factor in mortality decline an examination of Nigerian data." Population Studies 33(3): 395-413.

Caldwell, J. C. and P. Caldwell. 1985. "Education and literacy as factors in health." In: S. B. Halstead, J. A. Walsh, and K. S. Warren (eds.) Good Health at Low Cost. New York, The Rockefeller Foundation, pp. 181-185. 
Chou, S.-Y., J.-T. Liu, G. Michael, and J. J Theodore. 2007. "Parental education and child health: evidence from a natural experiment in Taiwan." NBER Working paper No. W13466.

Cleland, J. G. and J. K. van Ginneken. 1988. "Maternal education and child survival in developing countries: The search for pathways of influence." Social Science and Medicine 27(12): 1357-1368.

DaVanzo, J. and J.-P. Habicht. 1986. "Infant mortality decline in Malaysia, 1946-1975: The roles of changes in variables and changes in the structure of relationships." Demography 23(2): 143-160.

Glewwe, P. 1999. "Why does mother's schooling raise child health in developing countries? Evidence from Morocco." The Journal of Human Resources 34(1): 124-159.

Govingdasamy, P. and B. M. Ramesh. 1997. "Maternal education and the utilization of maternal and child health services in India." National Family Health Survey Subject Reports vol.5. Mumbai, India, Calverton, Maryland, International Institute for Population Sciences Macro International Inc.

Heaton, T. B., R. Forste, J. P. Hoffmann, and D. Flake. 2005. "Cross-national variation in family influences on child health." Social Science and Medicine 60: 97-108.

Hertel-Fernandez, A. W., A. E. Giustib, and J. M. Sotelob. 2007. "The Chilean infant mortality decline: improvement for whom? Socioeconomic and geographic inequalities in infant mortality, 1990-2005." Bulletin of the World Health Organization 85(10): 798-804.

Hobcraft, J. N. (1993). "Women's education, child welfare and child survival: a review of the evidence." Health Transitiion Review 3(2): 159-173.

Hobcraft, J. N., J. W. McDonald, and S. O. Rutstein. 1984. "Socio-economic factors in infant and child mortality: A cross-national comparison." Population Studies 38(2): 193-223.

Jalan, J. and M. Ravallion. 2003. "Does piped water reduce diarrhea for children in rural India?" Journal of Econometrics 112: 153-173.

Kovsted, J., C. C. Portner, and F. Tarp. 2002. "Child health and mortality: Does health knowledge matter?” Journal of African Economies 11(4): 542-560.

MeasureDHS+. 2008. Description of the Demograhic and Health Surveys. Individual Recode Data File, ORC Macro. Version 1.0.

Mensch, B., H. Lentzner, and S. Preston. 1985. "Socio-economic differentials in child mortality in developing countries." New York, United Nations.

Panis, C. W. A. and L. A. Lillard 1994. "Health inputs and child mortality: Malaysia." Journal of Health Economics 13: 455-489.

Pebley, A. R., N. Goldman, and G. Rodriguez. 1996. "Prenatal and delivery care and childhood immunization in Guatemala: Do family and community matter?" Demography 33(2): 231-247.

Peña, R., J. Liljestrand, E. Zelaya, and L. A. Persson. 1999. "Fertility and infant mortality trends in Nicaragua 1964-1993. The role of women's education." Journal of Epidemiology and Community Health 53: 132-137.

Raghupathy, S. 1996. "Education and use of maternal care in Thailand." Social Science and Medicine 43(4): 459-471. 
Rutstein S. O. and G. Rojas. 2006. Guide to DHS Statistics. Calverton, Maryland, ORC Macro.

Rutstein S. O. and K. Johnson. 2004. The DHS wealth index. DHS Comparative Reports. Calverton, Maryland USA.

Schultz, T. P. 1993. "Mortality decline in the low-Income world: Causes and consequences." The American Economic Review 83(2): 337-342.

Semba, R. D., S. De Pee, K. Kraemer, K. Sun, A. Thorne-Lyman, R. Moench-Pfanner, M. Sari, N. Akhter, and M. W. Bloem. 2009. "Purchase of drinking water is associated with increased child morbidity and mortality among urban slum-dwelling families in Indonesia." International Journal of Hygiene and Environmental Health 212(4): 387397.

Song, S. and S. A. Burgard. 2008. "Social conditions and infant mortality in China: A test of the fundamental cause hypothesis." California Center for Population Research On-Line Working Paper Series CCPR-013-08.

Strauss, J. 1990. "Households, communities, and preschool children's nutrition outcomes: evidence from rural Cote d'Ivoire." Economic Development and Cultural Change 38(2): 231-261.

Stuebing, K. W. 1997. "Maternal schooling and comprehension of child health information in urban Zambia: is literacy a missing link in the maternal schoolingchild health relationship?" Health Transitiion Review 7: 149-169.

Thomas, D., J. Strauss, and M. H. Henriques. 1990. "Child survival, height for age and household characteristics in Brazil." Journal of Development Economics 33(2): 197-234.

Thomas, D., J. Strauss, and M. H. Henriques. 1991. “How does mother's education affect child height?" The Journal of Human Resources 26(2): 183-211.

Victora, C. G., S. R. A. Huttly, F. C. Barros, C. Lombardi, and J. P. Vaughan. 1992. "Maternal education in relation to early and late child health outcomes: Findings from a Brazilian cohort study." Social Science and Medicine 34(8): 899-905.

Wolfe, B. L. and J. R. Behrman 1987. "Women's Schooling and Children's Health." Journal of Health Economics 6: 239-254.

Wong, E. L., B. M. Popkin, D. K. Guilkey, and J. S. Akin. 1987. "Acessibility, quality of care and prenatal care use in the Philippines." Social Science and Medicine 24(11): 927-944. 


\section{Appendix}

Table A.1:

Full set of countries and Demographic and Health Surveys used in the empirical analysis

\begin{tabular}{|c|c|c|c|c|c|c|}
\hline Country & $\begin{array}{c}\text { Country } \\
\text { code and } \\
\text { phase }\end{array}$ & Year & $\begin{array}{l}\text { Sample } \\
\text { size }\end{array}$ & $\begin{array}{l}\text { Infant } \\
\text { deaths }\end{array}$ & $\begin{array}{c}\text { Mean years } \\
\text { of schooling, } \\
\text { below } \\
\text { median } \\
\text { education }\end{array}$ & $\begin{array}{c}\text { Mean } \\
\text { years of } \\
\text { schooling, } \\
\text { above } \\
\text { median } \\
\text { education }\end{array}$ \\
\hline Bangladesh & BD5 & 2007 & 9,429 & 315 & 0 & 6.6 \\
\hline Benin & BJ5 & 2006 & 13,154 & 635 & 3.1 & 11.4 \\
\hline Bolivia & $\mathrm{BO} 4$ & 2003 & 11,691 & 507 & 1.8 & 8.8 \\
\hline Burkina Faso & BF4 & 2003 & 9,059 & 557 & 0 & 5.6 \\
\hline Cambodia & KH5 & 2005 & 10,320 & 569 & 0 & 6.6 \\
\hline Cameroon & CM4 & 2004 & 7,138 & 444 & 4.2 & 11.3 \\
\hline Chad & TD4 & 2004 & 4,405 & 360 & 0 & 4.3 \\
\hline Colombia & $\mathrm{CO} 4$ & 2005 & 25,442 & 450 & 4.9 & 12.3 \\
\hline Congo & CG4 & 2005 & 4,888 & 236 & 1.7 & 8.3 \\
\hline Congo, DR & CD5 & 2007 & 6,715 & 469 & 4.2 & 9.9 \\
\hline Dominican Rep. & DR5 & 2007 & 18,723 & 475 & 1.4 & 12.2 \\
\hline Egypt & EG5 & 2008 & 13,944 & 221 & 0 & 5.2 \\
\hline Ethiopia & ET4 & 2005 & 8,934 & 493 & 1 & 9.4 \\
\hline Ghana & GH4 & 2003 & 3,830 & 190 & 0 & 6.4 \\
\hline Guinea & GN4 & 2005 & 6,009 & 459 & 7.3 & 12.9 \\
\hline Haiti & HT5 & $2005 / 06$ & 6,159 & 309 & 0 & 8 \\
\hline Honduras & HN5 & 2005 & 13,371 & 267 & 0.4 & 7.2 \\
\hline India & IA5 & $2005 / 06$ & 81,248 & 2627 & 4.3 & 11.1 \\
\hline Indonesia & ID5 & 2007 & 29,110 & 772 & 8.4 & 13.7 \\
\hline Jordan & JO5 & 2007 & 9,457 & 141 & 3.9 & 10.1 \\
\hline Kenya & KE4 & 2003 & 5,541 & 299 & 1.3 & 6.3 \\
\hline Lesotho & LS4 & 2004 & 4,517 & 267 & 0 & 7.4 \\
\hline Liberia & LB5 & 2004 & 5,409 & 323 & 5.6 & 9.9 \\
\hline Malawi & MW4 & 2004 & 8,764 & 593 & 1.3 & 7.6 \\
\hline Mali & ML5 & 2006 & 11,001 & 865 & 1.3 & 7.6 \\
\hline Morocco & MA4 & $2003 / 04$ & 8,337 & 234 & 1.6 & 7.8 \\
\hline
\end{tabular}

Table continued on the next page 


\begin{tabular}{|c|c|c|c|c|c|c|}
\hline \multicolumn{7}{|c|}{ Table A.1 (continued) } \\
\hline Country & $\begin{array}{c}\text { Country } \\
\text { code and } \\
\text { phase }\end{array}$ & Year & $\begin{array}{l}\text { Sample } \\
\text { size }\end{array}$ & $\begin{array}{l}\text { Infant } \\
\text { deaths }\end{array}$ & $\begin{array}{c}\text { Mean years } \\
\text { of schooling, } \\
\text { below } \\
\text { median } \\
\text { education }\end{array}$ & $\begin{array}{c}\text { Mean } \\
\text { years of } \\
\text { schooling, } \\
\text { above } \\
\text { median } \\
\text { education }\end{array}$ \\
\hline Mozambique & MZ4 & 2003 & 9,231 & 734 & 1.3 & 7.6 \\
\hline Namibia & NM5 & $2006 / 07$ & 6,268 & 250 & 5.6 & 11.8 \\
\hline Nepal & NP5 & 2006 & 7,473 & 256 & 0 & 6.4 \\
\hline Niger & NI5 & 2006 & 6,913 & 378 & 0 & 5.6 \\
\hline Nigeria & NG4 & 2003 & 4,826 & 363 & 0 & 8.3 \\
\hline Pakistan & PK5 & $2006 / 07$ & 8,396 & 427 & 0 & 7.8 \\
\hline Peru & PE4 & $2004 / 08$ & 8,155 & 176 & 4.7 & 12.6 \\
\hline Philippines & PH4 & 2003 & 8,343 & 185 & 7.2 & 14.1 \\
\hline Rwanda & RW4 & 2005 & 6,722 & 455 & 0.8 & 6.5 \\
\hline Senegal & SN4 & 2005 & 9,100 & 478 & 0 & 6.3 \\
\hline Swaziland & SZ5 & 2006 & 3,280 & 205 & 4.7 & 11.2 \\
\hline Tanzania & $\mathrm{TZ4}$ & 2004 & 7,215 & 425 & 4.4 & 11.6 \\
\hline Uganda & UG5 & 2006 & 6,123 & 353 & 1.4 & 7.5 \\
\hline Zambia & ZM5 & 2007 & 5,137 & 293 & 3.1 & 8.8 \\
\hline Zimbabwe & ZW5 & $2005 / 06$ & 5,946 & 233 & 5.7 & 10.3 \\
\hline
\end{tabular}

